\title{
Investigation on the Effectiveness of Aqueous Carbonated Lime in Producing an Alternative Cementitious Material
}

\author{
Byung-Wan Jo*, Sumit Chakraborty, Ji Sun Choi, and Jun Ho Jo
}

\author{
(Received September 3, 2015, Accepted January 31, 2016, Published online February 19, 2016)
}

\begin{abstract}
With the aim to reduce the atmospheric $\mathrm{CO}_{2}$, utilization of the carbonated lime produced from the aqueous carbonation reaction for the synthesis of a cementitious material would be a promising approach. The present investigation deals with the aqueous carbonation of slaked lime, followed by hydrothermal synthesis of a cementitious material utilizing the carbonated lime, silica fume, and hydrated alumina. In this study, the aqueous carbonation reaction was performed under four different conditions. The TGA, FESEM, and XRD analysis of the carbonated product obtained from the four different reaction conditions was performed to evaluate the efficacy of the reaction conditions used for the production of the carbonated lime. Additionally, the performance of the cementitious material was verified analyzing the physical characteristics, mechanical property and setting time. Based on the results, it is demonstrated that the material produced by the hydrothermal method possesses the cementing ability. Additionally, it is revealed that the mortar prepared using the alternative cementitious material yields $33.8 \pm 1.3 \mathrm{MPa}$ compressive strength. Finally, a plausible reaction scheme has been proposed to explain the overall performances of the aqueous carbonation as well as the hydrothermal synthesis of the cementitious material.
\end{abstract}

Keywords: carbon dioxide emission, aqueous carbonation, $\mathrm{CO}_{2}$ sequestration, hydrothermal synthesis, cementitious material.

\section{Introduction}

Nowadays, the world's increasing need is to control the global warming and environmental pollution minimizing the emission of the climate changing gasses (Jacobsen et al. 2013; Phair 2006). It is stated in the Kyoto protocol 6 that including the carbon dioxide, some other gasses such as methane, nitrous oxide, sulfur dioxide, sulfur hexafluoride, hydrocarbons, chlorofluorocarbons, and perfluorocarbons, etc., are responsible for the greenhouse effect and global warming. Usually, the fossil fuel is considered to be a major energy source worldwide, which emits a massive carbon dioxide during burning (Siegenthaler and Oeschger 1987; Keeling et al. 1995; Olajire 2013). Conversely, the cement production method emits an enormous amount of carbon dioxide. It is reported elsewhere that the production of the 1-ton cement emits $\sim 830 \mathrm{~kg}$ of $\mathrm{CO}_{2}$ (Amato 2013; Schrabback 2010). Additionally, it is also reported that the level of the $\mathrm{CO}_{2}$ has increased $\sim 30 \%$ since the beginning of the industrial revolution (Siegenthaler and Oeschger 1987; Keeling et al. 1995). The current level of the atmospheric carbon dioxide $\left(\mathrm{CO}_{2}\right)$ is measured to be 400 ppm (Amato 2013; Schrabback 2010 ), which is projected to be increased up to $\sim 800 \mathrm{ppm}$ by

Department of Civil and Environmental Engineering, Hanyang University, Seoul 133791, Korea.

*Corresponding Author; E-mail: joycon@hanmail.net Copyright (C) The Author(s) 2016. This article is published with open access at Springerlink.com the end of this century without taking a courageous step (Feely et al. 2004). Hence, an immediate practical plan is required to reduce the $\mathrm{CO}_{2}$ emission. Additionally, the awareness of the people needs to be increased in controlling the mentioned threats. Therefore, it is essential to develop an alternative technology for minimizing the $\mathrm{CO}_{2}$ released by man-made and industrial activities.

With the aim to reduce the atmospheric $\mathrm{CO}_{2}$, the attention of the scientists and the technologists was attracted towards the mineral carbonization. The capture or storage of $\mathrm{CO}_{2}$ in the geological form is one of the most promising approaches to reduce the atmospheric $\mathrm{CO}_{2}$ (Gerdemann et al. 2007; Chizmeshya et al. 2007; Chen et al. 2006). The numerous investigations were executed to reduce the atmospheric carbon dioxide by in-situ or the ex-situ mineral sequestration method. Mineral carbonation process can able to minimize the atmospheric $\mathrm{CO}_{2}$ transforming into the stable carbonate minerals, such as calcite $\left(\mathrm{CaCO}_{3}\right)$, dolomite $\left(\mathrm{CaMg}\left(\mathrm{CO}_{3}\right)_{2}\right)$, magnesite $\left(\mathrm{MgCO}_{3}\right)$ and siderite $\left(\mathrm{FeCO}_{3}\right)$ (Metz et al. 2005). The mineral carbonation is reported to be an exothermic process (Olajire 2013). It takes place at normal temperature. Equation 1 shows the chemistry of the mineral carbonation reaction.

$$
\mathrm{MO}+\mathrm{CO}_{2} \rightarrow \mathrm{MCO}_{3}+(\text { Heat })
$$

Although, an adequate research report is available related to the mineral carbonation (Huijgen and Comans 2005; Huijgen et al. 2007; Hanchen et al. 2008; Huijgen et al. 2006, 2004), however, a very few of those techniques are utilized practically. Recently, some other processes such as 
the precipitated calcium carbonate formation, carbonation using brines, accelerated weathering of limestone and straightforward carbonation are also reported to consume the atmospheric $\mathrm{CO}_{2}$ (Chen et al. 2006; Huijgen and Comans 2005; Hanchen et al. 2008). Additionally, the carbonation of concrete, as well as the calcium hydroxide, is also reported to reduce the atmospheric $\mathrm{CO}_{2}$ (Galan et al. 2010; Han et al. 2011). Currently, some investigations have been executed to reduce the $\mathrm{CO}_{2}$ emission during the cement production by replacing the clinker with supplementary materials such as natural pozzolans, fly ash, and slag, etc (Schrabback 2010; Criado et al. 2010; Juenger et al. 2011; Amato 2013; Dinakar et al. 2013; Jeon et al. 2015; Kotwal et al. 2015; Roychand et al. 2016). Additionally, some alternative cementitious materials are produced by the alkali activation of the pozzolanic minerals such as ground granulated blast furnace slag, metakaolin and fly ash, etc (Dinakar et al. 2013; Kim et al. 2013; Kar et al. 2014; Jeon et al. 2015; Chindaprasirt and Cao 2015). Moreover, it is reported that an alternative cementitious material can be produced by the hydrothermal method utilizing geomaterials to reduce the $\mathrm{CO}_{2}$ emission during the cement production (Jo et al. 2014a, b). The synthesized cementitious material reveals benefits in controlling the physical and mechanical performances of the mortar and concrete. In fact, the geopolymers are composed of aluminosilicate minerals, which has the ability to be hard and sturdy, eventually, lead to gain strength $(\mathrm{Xu}$ and Van Deventer 2000; Kar et al. 2014). Although an adequate attention has been paid to reduce the $\mathrm{CO}_{2}$ emission. However, the utilization of the carbonated material in producing the cementitious material has yet to be investigated adequately. Very recently, we have reported the hydrothermal synthesis of a carbon dioxidestored cementitious material in controlling the performances of the mortar (Jo et al. 2015).

Reviewing the literature, it is apparent that the utilization of the aqueous carbonated slaked lime for the production of a cementitious material has not studied yet. Hence, In this investigation, we have studied the aqueous carbonation of the slaked lime, followed by hydrothermal synthesis of a cementitious material utilizing the carbonated lime infused with hydrated silica and alumina. The overall process is expected to be beneficial in controlling the atmospheric $\mathrm{CO}_{2}$. Although the aqueous carbonation of slaked lime can not reduce the ultimate $\mathrm{CO}_{2}$ emission, nevertheless, it would transform the atmospheric $\mathrm{CO}_{2}$ to a stable material.

\section{Experimental Section}

A systematic experimental program was arranged for the aqueous carbonation of slaked lime and the hydrothermal synthesis of an alternative cementitious material. The details of the experimental procedure and characterization techniques are described clearly in the succeeding sections.

\subsection{Aqueous Carbonation of the Slaked Lime}

The slaked lime $\left(\mathrm{Ca}(\mathrm{OH})_{2}\right)$ powder $(98 \%$ pure) was used as a primary reactant for the carbonation reaction. The used slaked lime contains some other oxide materials such as $\mathrm{MgO}<0.4 \%, \quad \mathrm{SiO}_{2}<0.8 \%, \quad \mathrm{Al}_{2} \mathrm{O}_{3}<0.5 \% \quad$ and $\mathrm{Fe}_{2} \mathrm{O}_{3}<0.3 \%$. An aqueous solution of the slaked lime was prepared using $0.865 \mathrm{~g}$ of dry slaked lime powder and $500 \mathrm{ml}$ of distilled water in a beaker. It is reported elsewhere that the solubility of the hydrated lime in water is $\sim 0.173$ at $20{ }^{\circ} \mathrm{C}$. Therefore, in this study, $0.173 \%$ slaked lime solution was prepared. In this investigation, the carbonation reaction was performed in a closed reactor. Figure 1 represents a schematic diagram of the reactor used in this investigation. In the reactor, a mass flow meter (MFC-100) was installed to control the carbon dioxide injection speed as well as to measure the mass of the injected $\mathrm{CO}_{2}$. Additionally, the instrument was associated with a $\mathrm{pH}$ measurement device (pHI-201), which was employed to record the change of $\mathrm{pH}$ during the carbonation reaction. After preparing the aqueous slaked lime solution, the beaker was placed into a Teflon made closed drum of the reactor to avoid the contamination of the other gasses and unwanted carbonation. Subsequently, the $\mathrm{CO}_{2}$ gas was purged into the reacting vessel for $20 \mathrm{~min}$ maintaining the temperature of the reaction system $21{ }^{\circ} \mathrm{C}$. In this study, the aqueous carbonation of the slaked lime was performed in four different conditions varying the agitation speed (viz., 200 and $450 \mathrm{RPM})$ and $\mathrm{CO}_{2}$ injection speed $(0.3$ and $0.51 / \mathrm{min})$. Table 1 presents the details of the reaction

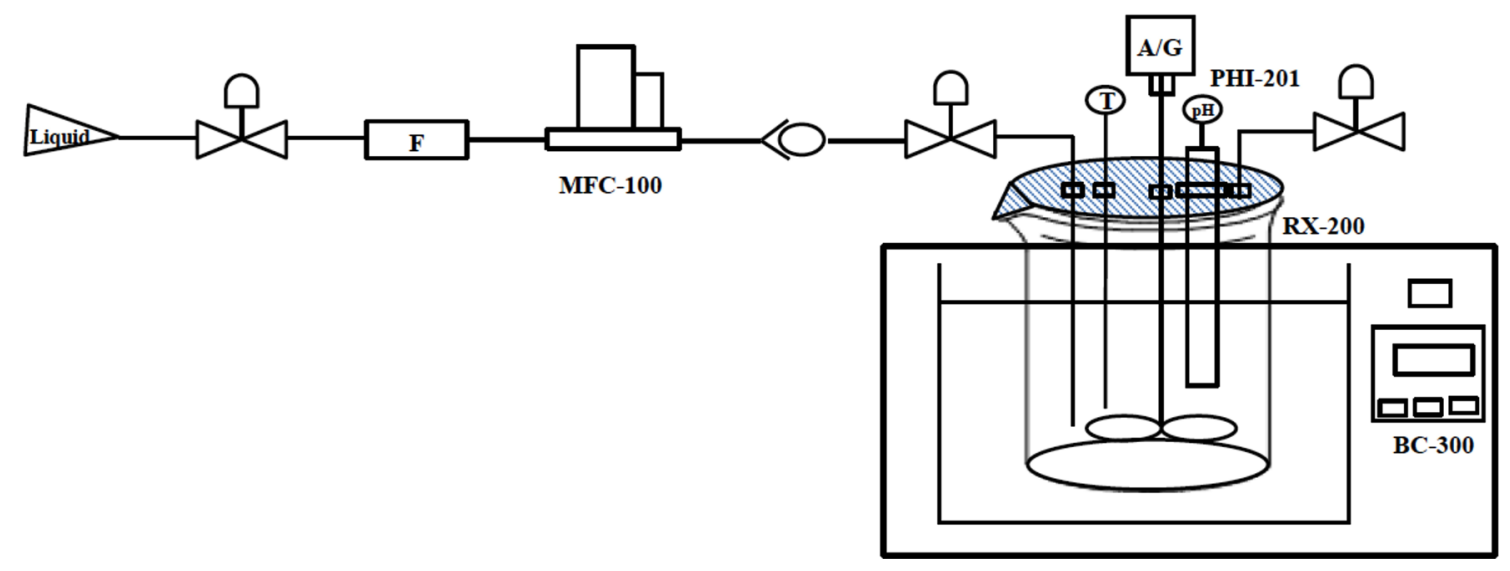

Fig. 1 Schematic presentation of the reactor for the aqueous carbonation reaction. 
Table 1 Summary of the conditions used for the aqueous carbonization of the slaked lime.

\begin{tabular}{c|c|c|c|c}
\hline $\begin{array}{c}\text { Reaction condition } \\
\text { code }\end{array}$ & $\begin{array}{c}\text { Agitation speed } \\
(\mathrm{RPM})\end{array}$ & $\begin{array}{c}\text { Temperature } \\
\left({ }^{\circ} \mathrm{C}\right)\end{array}$ & $\begin{array}{c}\mathrm{CO}_{2} \text { injection } \\
\text { speed (1/min) }\end{array}$ & $\begin{array}{c}\text { Reaction } \\
\text { time }(\mathrm{min})\end{array}$ \\
\hline \hline A & 200 & 21 & 0.3 & 20 \\
\hline B & 200 & 21 & 0.5 & 20 \\
\hline C & 450 & 21 & 0.3 & 20 \\
\hline D & 450 & 21 & 0.5 & 20 \\
\hline
\end{tabular}

conditions used in this study. After completion of the reaction, the precipitates were filtered off using a Whatman 41 filter paper and an aspirator. Thereafter, the moisture was detached from the precipitates using a freeze dryer. Finally, the carbonated product was stored in a vacuum desiccator and allowed to characterize. In this investigation, the carbonation reaction was repeated three times to obtain an average result.

\subsection{Hydrothermal Synthesis of the Cementitious Material}

The carbonated lime produced from the aqueous carbonation method was used for the hydrothermal synthesis of an alternative cementitious material. Initially, $180 \mathrm{~g}$ of silica fume was mixed with the $700 \mathrm{ml}$ of water in a beaker using a magnetic stirrer, followed by mixing with $120 \mathrm{~g}$ of carbonated lime. Simultaneously, $60 \mathrm{~g}$ of sodium hydroxide dissolved in $700 \mathrm{ml}$ of water in an another beaker, followed by mixing with $100 \mathrm{~g}$ of sodium aluminate. Afterward, $140 \mathrm{~g}$ of triethanolamine (TEA) was added to the sodium aluminate solution for preventing the coagulation of aluminium hydroxide from the solution. Thereafter, the mixtures were agitated for $24 \mathrm{~h}$. A thick gel was produced from the mixture of silica fume and carbonated lime. Conversely, a comparatively thin gel was produced from the hydrated alumina and TEA mixture. Subsequently, the thick gel was added gently to the low-density gel with a constant stirring, followed by $3 \mathrm{~h}$ sonication. The mixed compound, thus, obtained was allowed to dry and crystallize in an oven at $105{ }^{\circ} \mathrm{C}$. Finally, the solid crystalline material obtained after 7 days of controlled heating was treated as an alternative cementitious material (ACM). A pictographic model for the hydrothermal synthesis of the carbonated lime based ACM is presented in Fig. 2. The solid oven-dried material was, then, ground to make a powder for preparing the mortar samples.

\subsection{Fabrication of the ACM Based Mortar Sample}

In this study, the mortar samples were fabricated using the $\mathrm{ACM}$, fine aggregate (sand), and the varying amounts of alkali activator $(50 \% \mathrm{NaOH}$ solution) and water. For a particular batch mixing of the ACM based mortar, $100 \mathrm{~g}$ of ACM was mixed with the $300 \mathrm{~g}$ of fine aggregate, followed by mixing with the required amount of alkali activator and water. In this investigation, a control mortar sample was also prepared using $100 \mathrm{~g}$ ordinary Portland cement, $300 \mathrm{~g}$ of sand and $60 \mathrm{ml}$ of water. Table 2 shows the mix proportion of the components used for the fabrication of the control and ACM based mortar. The mortar mixture obtained after mixing of the components was, then, cast immediately in the $50 \mathrm{~mm}$ side cubic molds and allowed to set for $24 \mathrm{~h}$. After

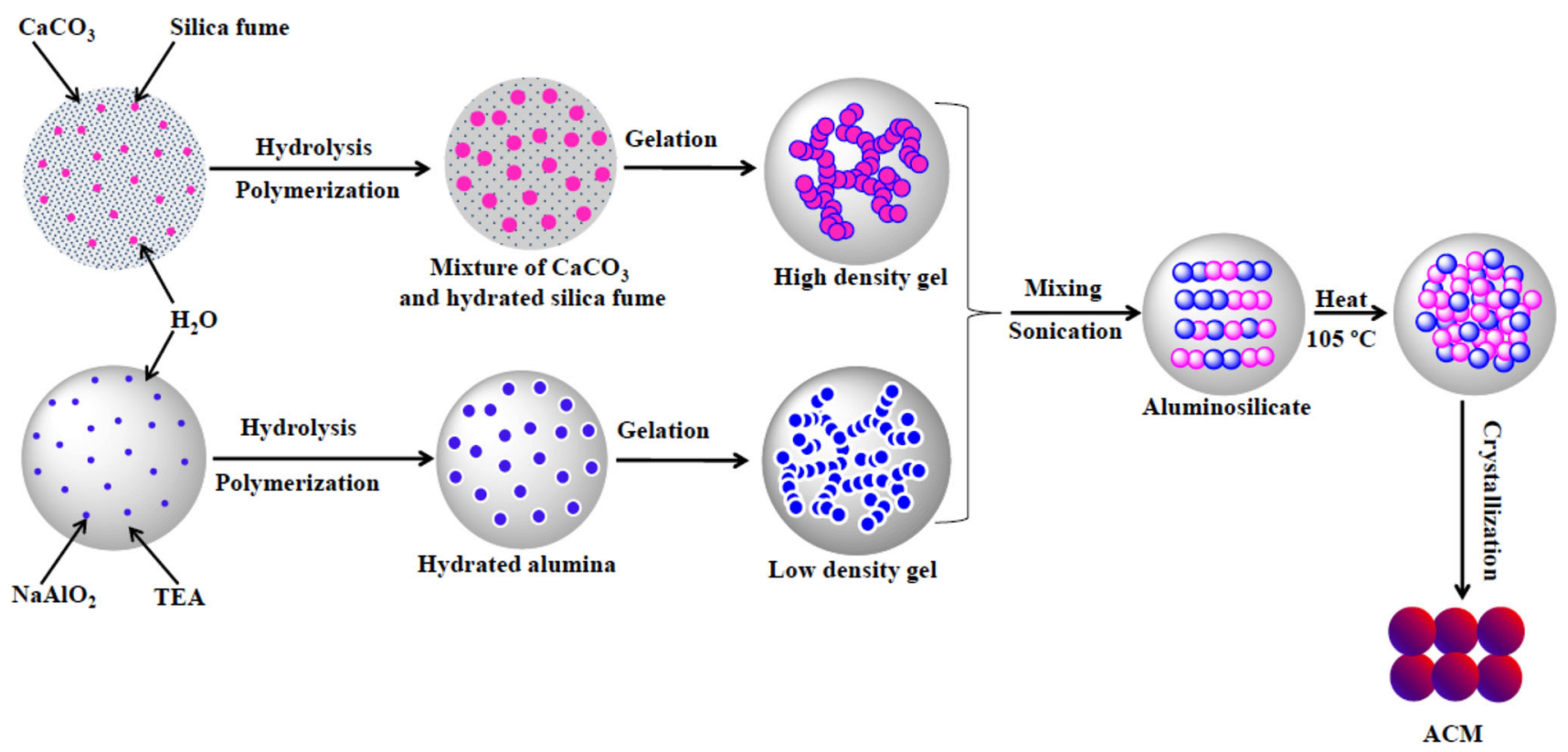

Fig. 2 The plausible model for the hydrothermal synthesis of the cementitious material utilizing carbonated material produced by the aqueous carbonation reaction. 
Table 2 Formulation code and the mix proportions of the components for the fabrication of the control cement mortar and ACM based mortar.

\begin{tabular}{c|c|c|c|c}
\hline \multirow{2}{*}{ Sample code } & \multicolumn{4}{|c}{ Mix proportioning of the components } \\
\cline { 2 - 5 } & Cement $(\mathrm{g})$ & Fine aggregate $(\mathrm{g})$ & Water $(\mathrm{ml})$ & Alkali activator $(\mathrm{ml})^{\mathrm{c}}$ \\
\hline \hline CCM & $100^{\mathrm{a}}$ & 300 & 60 & - \\
\hline ACM-M1 & $100^{\mathrm{b}}$ & 300 & 60 & - \\
\hline ACM-M2 & $100^{\mathrm{b}}$ & 300 & 30 & 30 \\
\hline ACM-M3 & $100^{\mathrm{b}}$ & 300 & - & 60 \\
\hline
\end{tabular}

a Ordinary portland cement.

b Alternative cementitious material.

c $50 \% \mathrm{NaOH}$ solution.

complete setting, the mortar samples were allowed to water cure for 28 days. The mortar samples were removed from the curing chamber and allowed to test after completion of the desired curing period.

\subsection{Characterizations}

The thermal analysis of the precipitates obtained from the aqueous carbonation reaction was performed using a thermogravimetric analyzer (TG-DTA 2020SA). In this experiment, exactly $10 \mathrm{mg}$ of the powder sample was used for the analysis. The experiment was conducted under a dynamic $\mathrm{N}_{2}$ atmosphere in the temperature range between 30 and $900{ }^{\circ} \mathrm{C}$ with a heating rate of $10{ }^{\circ} \mathrm{C} / \mathrm{min}$. In this investigation, each sample was analyzed three times to get an average result.

The X-ray diffraction pattern of the precipitates obtained from the aqueous carbonation reaction was recorded using an X-ray diffractometer (Ultima III). The instrument produced a monochromatic X-ray beam of the wavelength $1.54 \AA$ using $\mathrm{CuK} \alpha$ radiation $(40 \mathrm{kV}, 40 \mathrm{~mA})$ and $\mathrm{Ni}$ filter. In this study, the X-ray diffraction pattern of the samples was recorded in the $2 \theta$ range between $10^{\circ}-60^{\circ}$, maintaining a scan speed of $1 \%$ min with a step difference of $0.02^{\prime \prime}$. Prior to analyzing the $\mathrm{X}$-ray diffraction pattern, the sample was packed into a rectangular hollow area of the glass made sample holder, followed by placing in the instrument.

The microstructure of the precipitates obtained from the aqueous carbonation reaction, the product obtained from the hydrothermal synthesis and the 28 days cured mortar was recorded using a field scanning electron microscope (JEOL JSM-6700F). Prior to analyzing the microstructure, a very thin gold was sputter coated on the surface of the moisturefree dried samples to avoid charging. Thereafter, samples were placed on the SEM stub and allowed to analyze. The digital scanning electron micrographs were recorded in $10-20 \mathrm{kV}$ accelerated voltage and $15 \mathrm{k} \times$ magnification.

The particle size analysis of the cementitious material obtained from the hydrothermal method was performed using LA-950 Laser particle size analyzer. For the particle size analysis, exactly $1 \mathrm{~g}$ of the oven-dried sample was fed into the PowderJet Dry Feeder of the LA-950 Laser particle size analyzer. Furthermore, the sample was analyzed based on the Mie scattering theory. In this instrument, two light sources viz., $5 \mathrm{~mW}, 650 \mathrm{~nm}$ red laser diode and $3 \mathrm{~mW}$,
$405 \mathrm{~nm}$ blue LED were used to analyze the particle size of the material. In the measurement array, the high-quality photodiodes were used to detect the scattered light over a wide range of angles.

The initial and final setting time of the alternative cementitious material obtained from the hydrothermal method was measured according to the KSL 5108 (2007). Usually, this standard method is used to measure the setting time of the hydraulic cement.

The compressive strength of the $50 \mathrm{~mm}$ side cubic alternative cementitious material (ACM) based mortar sample was measured using a universal testing machine (Shimadzu, CCM-200A) with a loading rate $0.06 \mathrm{MPa} / \mathrm{min}$ in accordance with the Korean standard KS F 2405 (2010).

\section{Results}

\section{1 pH Analysis of the Carbonation Reaction Medium}

Figure 3 depicts the $\mathrm{pH}$ variation of the reaction medium with the increase in reaction time. In this study, the $\mathrm{pH}$ of the reaction medium was measured at the $1 \mathrm{~min}$ interval. From the figure, it is observed that irrespective of the reaction conditions, the $\mathrm{pH}$ of the reaction medium decreases

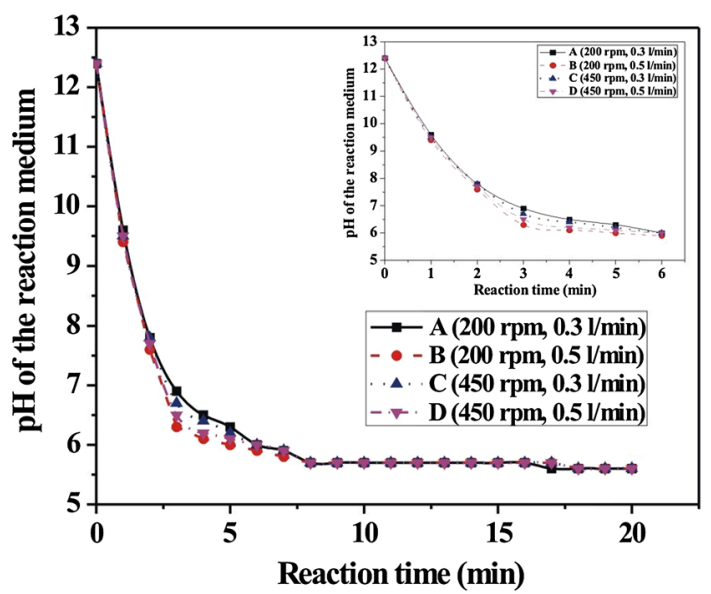

Fig. $3 \mathrm{pH}$ variation of the aqueous carbonation reaction medium as function of the reaction time. 
gradually up to 5 min of the reaction, followed by keeping constant with the progress in reaction. Prior to the carbonation reaction started (before $\mathrm{CO}_{2}$ purged), the $\mathrm{pH}$ of the reaction medium is measured to be 12.4 , which is measured to be $\sim 6.5$ after $5 \mathrm{~min}$ of the reaction started. Interestingly, the decrement of $\mathrm{pH}$ is observed to be different for the different reaction conditions (inset figure of the Fig. 3). The decrement of $\mathrm{pH}$ for the reaction condition $\mathrm{B}$ is observed to be higher as compared to that of the reaction condition $\mathrm{D}, \mathrm{C}$ and $\mathrm{A}$. Additionally, the order of $\mathrm{pH}$ decrement of the four different reaction conditions is found to be $\mathrm{B}>\mathrm{D}>\mathrm{C}>\mathrm{A}$. Hence, It is indicated that the rapid carbonation reaction occurs in the reaction condition $\mathrm{B}$ as compared to that of the other three conditions. The $\mathrm{pH}$ of the carbonation reaction medium is reduced to be due to the formation of the carbonic acid, which neutralizes the saturated solution of the slaked lime. During the reaction, the lime solution reacts with the carbonic acid, which in turn leads to produce the calcium carbonate and water. As a consequence, the concentration of $\mathrm{OH}^{-}$in the reaction system decreases. Eventually, the $\mathrm{pH}$ of the reaction system decreases (Olajire 2013). The $\mathrm{pH}$ of the reaction medium decreases continuously until the lime molecules are available for the carbonation. After complete neutralization of the lime molecules (after $6 \mathrm{~min}$ of the reaction started), the solution becomes $\mathrm{CO}_{2}$ rich $(\mathrm{pH}=5-6)$, which restrains to reduce the $\mathrm{pH}$.

\subsection{Quantification of the $\mathrm{CO}_{2}$ Consumption}

Table 3 represents the moles of reactants and products of the aqueous carbonation reaction. In this study, the experiment was repeated three times to identify the most effective reaction condition. After measuring the mass of the reactant and products, the moles of $\mathrm{CO}_{2}$ consumed in the carbonation reaction in four different reaction conditions are measured. From the table, the moles of $\mathrm{CO}_{2}$ (average value) consumed in the four different carbonation reaction conditions such as $\mathrm{A}, \mathrm{B}, \mathrm{C}$ and $\mathrm{D}$ are measured to be $0.0107 \pm 0.0004$, $0.0118 \pm 0.0008,0.0100 \pm 0.0004$, and $0.0112 \pm 0.0011$, respectively. It is well known that the $1 \mathrm{~mol}$ of lime reacts with $1 \mathrm{~mol}$ of $\mathrm{CO}_{2}$ to produce $1 \mathrm{~mol}$ of calcium carbonate (Olajire 2013). Viewing in light of the theoretical prediction, it is assumed that the $0.0117 \mathrm{~mol}$ of slaked lime would react with $0.0117 \mathrm{~mol}$ of $\mathrm{CO}_{2}$ to produce $0.0117 \mathrm{~mol}$ of calcium carbonate. However, in this investigation, all four reaction conditions do not follow the theoretical prediction conveniently. As presented in Table 3, the reaction conditions B and D nearly follow the theoretical prediction. From the table, it is envisaged that in the reaction condition $\mathrm{B}$ and $\mathrm{D}$, $0.0117 \mathrm{~mol}$ of slaked lime react with $0.0118 \pm 0.0008$ and $0.0112 \pm 0.0011 \mathrm{~mol}$ of $\mathrm{CO}_{2}$, respectively, and produces $0.0116 \pm 0.0003$ and $0.0111 \pm 0.0002 \mathrm{~mol}$ of calcium carbonate, respectively. Additionally, the $\%$ of $\mathrm{CO}_{2}$ consumption in four different reaction conditions such as $\mathrm{A}, \mathrm{B}$, $\mathrm{C}$ and $\mathrm{D}$ is calculated to be $91.2 \pm 3.0,100.1 \pm 6.8$ $85.5 \pm 3.1$ and $96.0 \pm 9.1 \%$, respectively. Figure 4 represents the moles of slaked lime (calcium hydroxide) and $\mathrm{CO}_{2}$ used and the moles of calcium carbonate produced in the theoretical carbonation reaction scheme and the four different carbonation reaction conditions such as $\mathrm{A}, \mathrm{B}, \mathrm{C}$ and D. The result reveals that the reaction condition $\mathrm{B}$ consumes higher amounts of $\mathrm{CO}_{2}$ and produces a greater amount of calcium carbonate as compared to that of the reaction condition D, A and C. Moreover, the reaction condition B follows the theoretical prediction more appropriately. Although, the impact of the reaction condition D is similar to the reaction condition $\mathrm{B}$. However, the reaction condition $\mathrm{D}$ (450 RPM agitation speed and $0.5 \mathrm{l} / \mathrm{min} \mathrm{CO}_{2}$ injection speed) would be a more energy consuming process as compared to that of the reaction condition B (200 RPM agitation speed and $0.5 \mathrm{l} / \mathrm{min} \mathrm{CO}_{2}$ injection speed). Therefore, the reaction condition $\mathrm{B}$ is considered to be the most suitable for the carbonation of slaked lime, which is used for the production of the carbonated lime in this investigation.

\subsection{Thermo Gravimetric Analysis (TGA) of the Carbonated Material}

The thermogravimetric analysis of the precipitates obtained from the aqueous carbonation reaction was performed to estimate the extent of carbonated product. In this investigation, the aqueous carbonation reaction in four different conditions was repeated three times to identify the most effective reaction condition. Figure 5 presents the TG thermogram (one replicate plot from each reaction condition) of the carbonated product obtained from the four different reaction conditions. As presented in the figure, the mass losses in the temperature range $400-550$ and $600-800{ }^{\circ} \mathrm{C}$ are observed to be due to the decomposition of the calcium hydroxide and calcium carbonate, respectively (Chakraborty et al. 2013). From the figure, it is envisaged that irrespective of the reaction conditions used for the carbonation of slaked lime, the thermogram of the carbonated products shows a prominent mass loss in the temperature range $600-830{ }^{\circ} \mathrm{C}$. However, the products obtained from the different reaction conditions show the different mass losses in the same temperature range. From the figure, the average mass loss attributed to be due to the decomposition of the calcium carbonate in four different reaction conditions, i.e., A, B, C and $\mathrm{D}$ is measured to be $29.4 \pm 2.3,39.2 \pm 2.5,31.9 \pm 1.8$ and $35.1 \pm 2.3 \%$, respectively. It indicates that the different carbonation reaction conditions produce different amounts of carbonated product. Additionally, it is observed that the reaction condition $\mathrm{B}$ produces a greater extent of calcium carbonate as compared to that of the reaction conditions, i.e., $\mathrm{A}, \mathrm{C}$ and D. Hence, the reaction condition $\mathrm{B}$ is considered to be most appropriate for the aqueous carbonation reaction. Additionally, it is apparent that the aqueous carbonation reaction successfully consumes the $\mathrm{CO}_{2}$ to produce a solid residue (calcium carbonate). This can be further clarified by the X-ray diffraction analysis as well as FESEM analysis.

\subsection{X-ray Diffraction Analysis of the Aqueous Carbonated Product}

The X-ray diffraction analysis of the aqueous carbonated lime was performed to identify the chemical phases present in the reaction product. Figure 6 depicts the X-ray diffraction pattern of the products obtained from the carbonation 


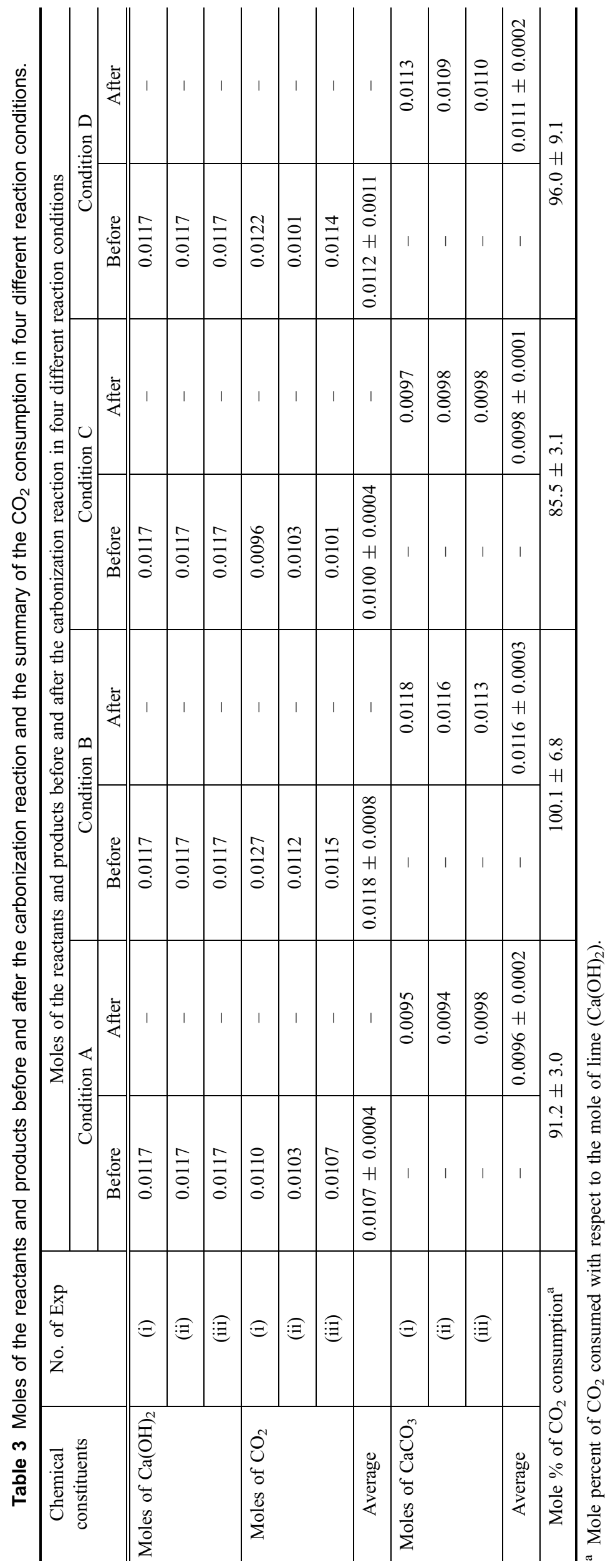




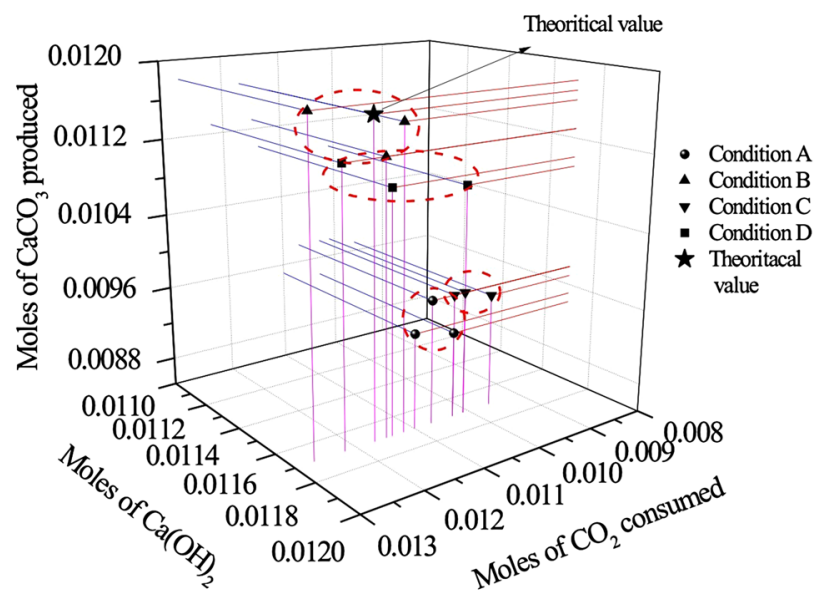

Fig. 4 Moles of slaked lime (calcium hydroxide) and $\mathrm{CO}_{2}$ used and the moles of calcium carbonate produced in the theoretical carbonation reaction scheme and the four different carbonation reaction conditions such as $A, B, C$, and $D$.

reaction in four different conditions. As presented in the figure, irrespective of the reaction condition used for the aqueous carbonation, the X-ray diffractogram of all samples possesses identical peaks. In the X-ray diffraction pattern, the characteristic peaks at the $2 \theta$ equal to $23.02^{\circ}, 29.41^{\circ}$, $35.97^{\circ}, 39.4,43.15,47.49$ and $48.51^{\circ}, 57.4^{\circ}$ appear to be due to the calcium carbonate (calcite) (Stutzman 1996; Jiao et al. 2009; Kontoyannis and Vagenas 2000; Han et al. 2011). Additionally, the very small peak at the $2 \theta$ equal to $56.42^{\circ}$ and $57.94^{\circ}$ appears to be due to the calcium carbonate also (Crowley 2010). Excluding the calcium carbonate peak, no other peak has been observed in the X-ray diffraction pattern. In fact, no peak for the calcium hydroxide (reactant) at the $2 \theta$ equal to $18.09^{\circ}, 28.66^{\circ}$, $34.09^{\circ}, 47.12^{\circ}, 50.79^{\circ}$ and $54.34^{\circ}$ (Stutzman 1996) has been observed. Hence, from the X-ray diffraction analysis, it is demonstrated that the aqueous carbonation reaction is considered to be very effective in producing the calcium

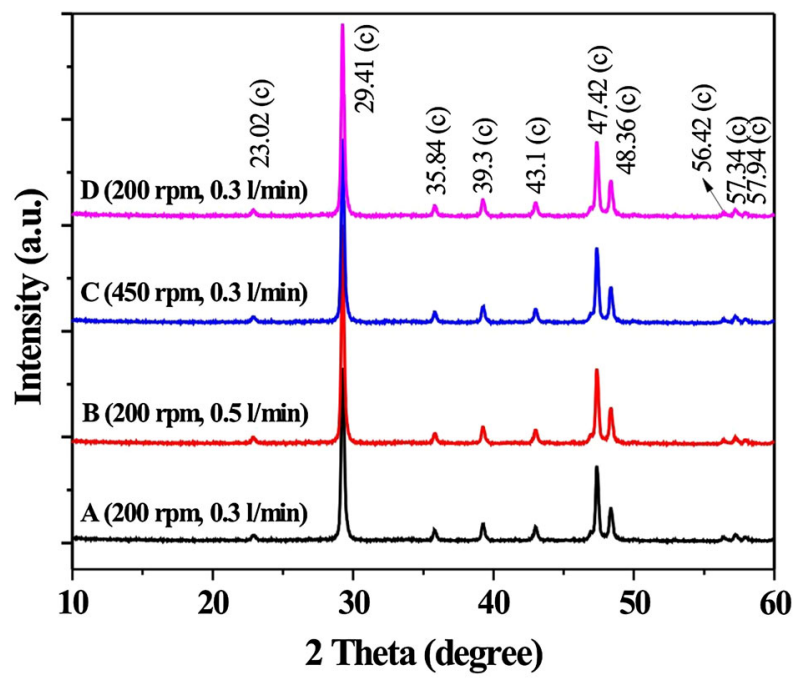

Fig. 6 X-ray diffraction patterns of the products obtained by the aqueous carbonation reaction in four different conditions.

carbonate from the slaked lime. Additionally, it is assumed that the aqueous carbonation of the slaked lime could be an efficient method to consume the environmental $\mathrm{CO}_{2}$.

\subsection{FESEM Analysis}

Figure 7 shows the microstructure of the precipitates obtained from the aqueous carbonation reaction in four different conditions. As presented in the figure, the images (Figs. 7a to 7d) obtained from the FESEM analysis are observed to be similar. Hence, it is confirmed that the reaction condition does not affect the microstructure of the carbonated product. Additionally, the microstructure of the carbonated compound obtained from the four different reaction condition is observed to be a crystalline. Generally, the calcium carbonate possesses three polymorphs such as calcite (rhombohedral crystal structure), vaterite (globe or oval shaped) and aragonite (needle-shaped crystal structure) (Han et al. 2011; Stutzman 1996). As evidenced by the XRD

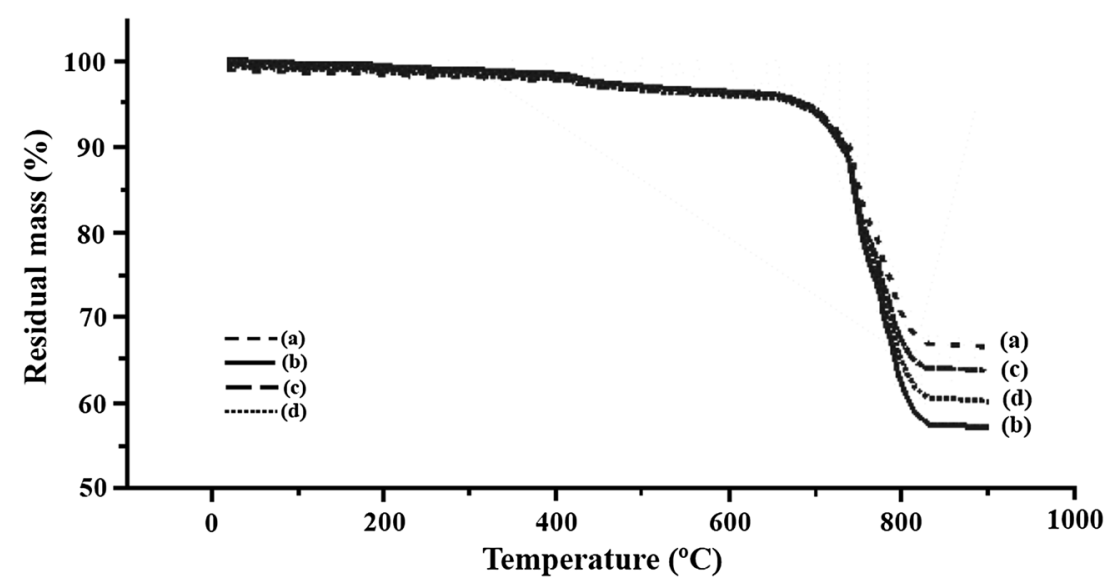

Fig. 5 TG thermograms of the products obtained from the aqueous carbonation reaction in four different conditions. In the figure $a$, $b, c$, and $d$ indicate the TG thermogram of the carbonated product obtained from the carbonation reaction condition $A, B, C$, and $D$, respectively. 

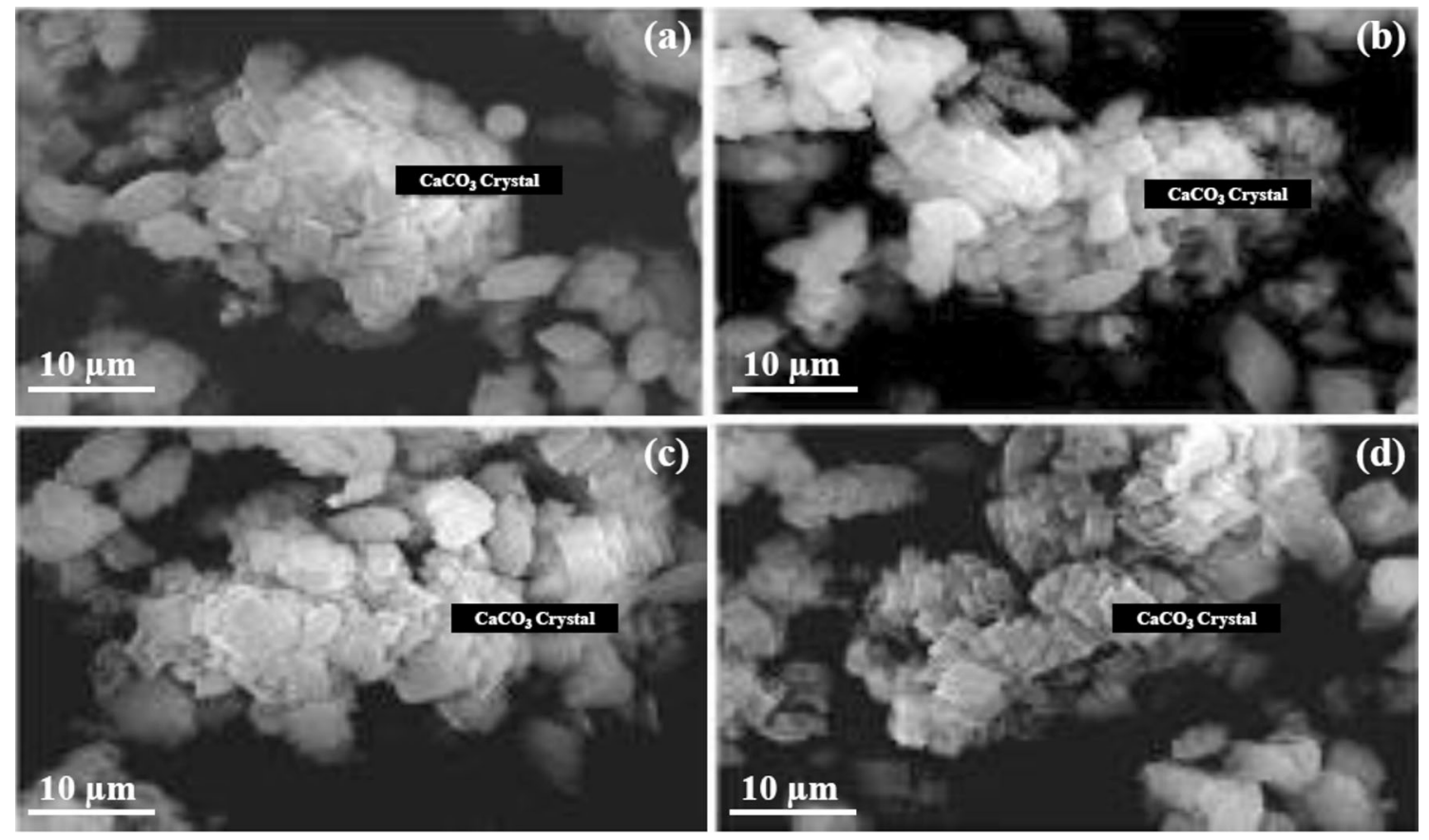

Fig. 7 FESEM images of the products obtained from the carbonation reaction of the slaked lime in four different conditions. a Product obtained from the reaction condition A, b Product obtained from the reaction condition B, $\mathbf{c}$ Product obtained from the reaction condition $\mathbf{C}, \mathbf{d}$ Product obtained from the reaction condition $\mathrm{D}$.
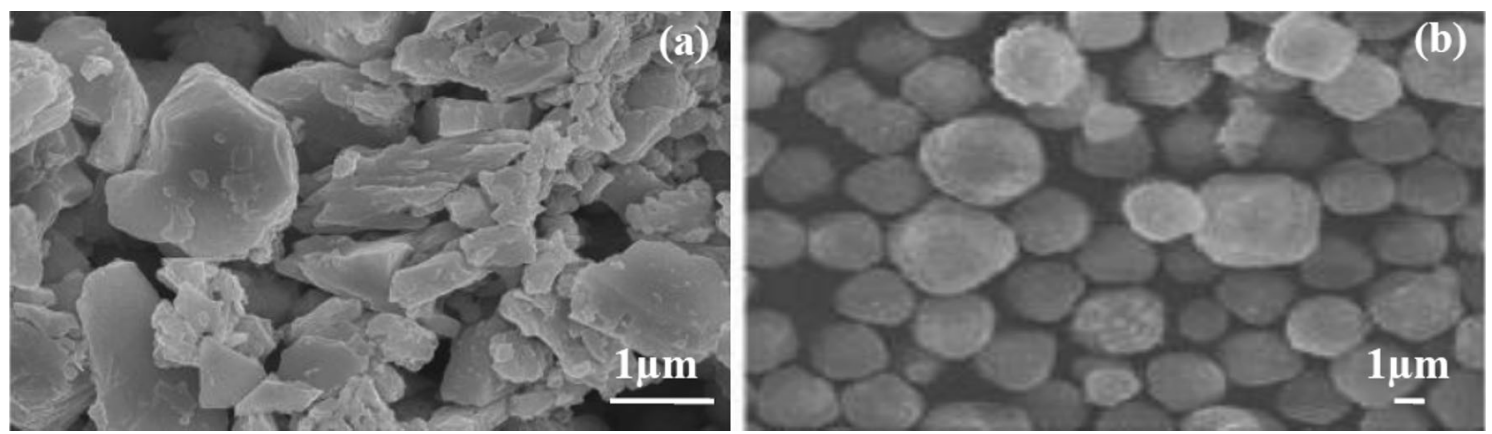

Fig. 8 FESEM images of the a ordinary Portland cement (Jo et al. 2014c) and b the cementitious material produced by hydrothermal synthesis method utilizing aqueous carbonated material.

analysis, irrespective of the reaction condition, the aqueous carbonation of slaked lime produces only calcite. Additionally, no crystal of the oval shaped and needle-shaped has been observed from the FESEM image of the carbonated product. Therefore, the crystal structure of the carbonated product (calcite) obtained from the aqueous carbonation reaction is considered to be rhombohedral.

Figures $8 \mathrm{a}$ and $8 \mathrm{~b}$ depict the FESEM images of the commercially available ordinary Portland cement and the cementitious material produced by the hydrothermal method, respectively. From the Fig. 8a, the particle of the ordinary Portland cement is observed to be irregular shaped. Whilst, the particles of the synthesized cementitious material are observed to be spherical shaped (Fig. 8b). Additionally, an excellent particle size distribution of the synthesized cementitious material has been observed. The TGA, XRD, and FESEM analysis demonstrate that the aqueous carbonation of slaked lime produces rhombohedral crystal of calcite. However, the microstructure of the alternative cementitious material does not contain any rhombohedral crystal of calcite. Therefore, it is considered that the entire amount of calcium carbonate is consumed in producing the alternative cementitious material. Hence, it is assessed that the hydrothermal method can able to store the carbonated lime as a cementitious material.

Figure 9 presents the microstructure of the 28 days cured control cement mortar (a) as well as the ACM based mortar (b). From Fig. 9b, it is envisaged that the alternative cementitious material can able to produce a compact microstructure after hydration. Comparing the FESEM image of the ACM based mortar with the control mortar, the microstructure of the ACM based mortar is observed to be similar to that of the ordinary Portland cement based mortar. It is a well-known that the development of the microstructure is a crucial factor in enhancing the mechanical strength of the cementitious material. In this study, the cementitious 

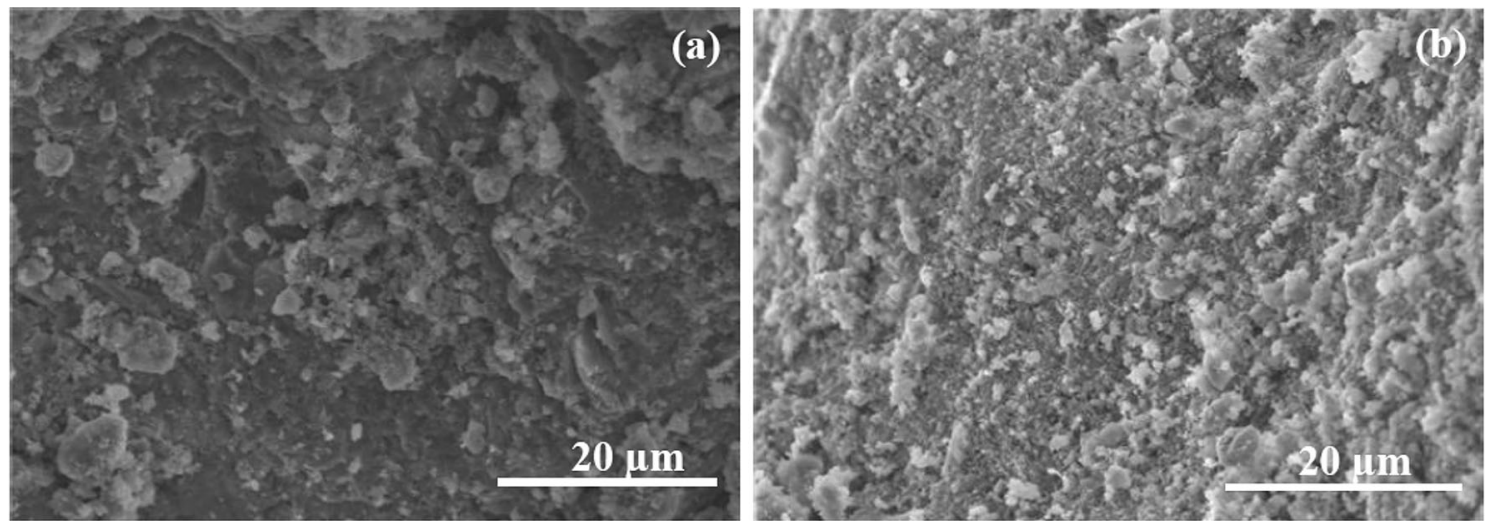

Fig. 9 FESEM images of the 28 days hydrated a control cement as well as the $\mathbf{b}$ ACM based mortar sample.

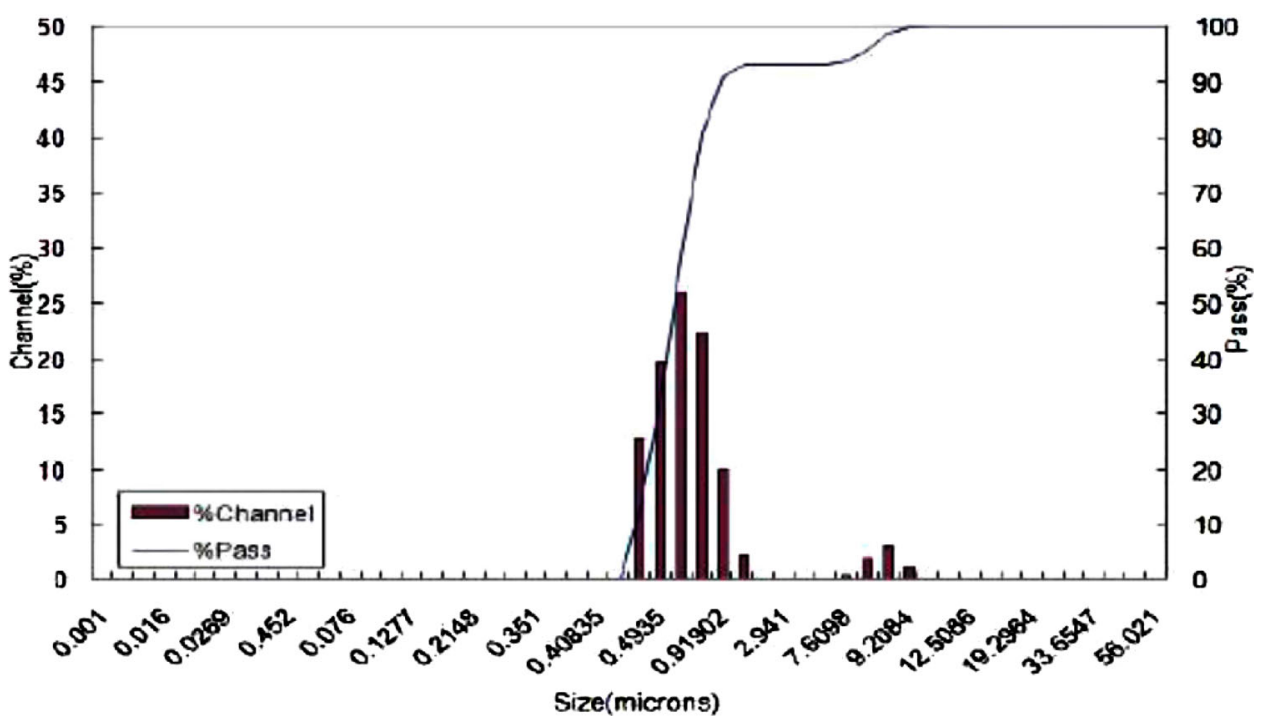

Fig. 10 The particle size distribution curve of the alternative cementitious material produced by the hydrothermal method.

material produced by the hydrothermal method utilizing carbonated lime develops a compact microstructure, which may contribute to improving the strength of the ACM based mortar.

\subsection{Particle Size Analysis of the Alternative Cementitious Material}

Figure 10 depicts the particle size distribution pattern of the alternative cementitious material. From the figure, it is envisaged that the particle size of the alternative cementitious material belongs in the range between $0.49-9.2 \mu \mathrm{m}$. The average particle size of the alternative cementitious material is measured to be $1.4 \mu \mathrm{m}$. Whilst, the particle size of the commercially available ordinary Portland cement is reported to be 10-30 $\mu \mathrm{m}$ (Jo et al. 2014c). Therefore, it is apparent that the particle size of the alternative cementitious material produced by the hydrothermal method is significantly smaller as compared to that of the commercially available Portland cement. Additionally, it is ascertained that the hydrothermal synthesis method is able to produce a spherical shaped submicron particle. Additionally, the specific gravity and fineness modulus of the alternative cementitious material produced by the hydrothermal method are measured to be 2.23 and $68,500 \mathrm{~cm}^{2} / \mathrm{g}$, respectively. Whilst, these are reported to be 3.15 and $2800 \mathrm{~cm}^{2} / \mathrm{g}$, respectively, for ordinary Portland cement (Jo et al. 2014c). As the alternative cementitious material possesses a smaller particle size and greater fineness modulus as compared to that of the $\mathrm{OPC}$, therefore, it is assumed that the alternative cementitious material would expose a greater surface area for the hydration reaction, which may lead to developing the early strength.

\subsection{Chemical Composition Analysis}

The oxide composition of the alternative cementitious was measured to evaluate the chemical characteristic. The oxide compositions of the alternative cementitious material are observed to be similar to that of the ordinary Portland cement. However, the amounts of the oxide phases are observed to be different. The mass (\%) of the oxide phases such as $\mathrm{SiO}_{2}, \mathrm{CaO}, \mathrm{Al}_{2} \mathrm{O}_{3}, \mathrm{Na}_{2} \mathrm{O}, \mathrm{Fe}_{2} \mathrm{O}_{3}$ of alternative cementitious material are measured to be 50.84, 9.69, 28.97, 
2 and $1.90 \%$, respectively. Whilst, the same are reported be 20.36, 64.33, 5.77, 0 and $2.84 \%$, respectively, for ordinary Portland cement (Jo et al. 2014a). Analyzing the oxide composition, it is envisaged that the alternative cementitious material contains a greater amount of $\mathrm{SiO}_{2}$ and $\mathrm{Al}_{2} \mathrm{O}_{3}$ as compared to that of the ordinary Portland cement. Therefore, it is expected that the alternative cementitious material may produce a geopolymer compound after hydration reaction (Mayer et al. 2013; Kar et al. 2014). Additionally, it is assumed that the geopolymer material would produce an interpenetrating net structure in the bulk of the mortar, which may lead to developing the strength of the ACM based mortar.

\subsection{Setting Time Analysis}

Setting time is an important characteristic of the of the hydraulic cement. Usually, the setting time of the cement is measured to know the time required to set and harden the cement sample. In this investigation, the setting time is measured to know the time required for setting and hardening of the alternative cementitious material. The initial and final setting time of the alternative cementitious material is measured to be $242 \pm 6$ and $528 \pm 5 \mathrm{~min}$, respectively. Whereas, the initial and final setting time of the ordinary Portland cement is measured to be $210 \pm 5$ and $300 \pm 8 \mathrm{~min}$, respectively (Jo et al. 2014a). It is reported elsewhere that the initial and final setting time of a standard hydraulic cement should be more than $60 \mathrm{~min}$ and less than $10 \mathrm{~h}$, respectively, at the ambient condition (KS L 5201 2013). In this study, the cementitious material produced by the hydrothermal method possesses a similar characteristic. Hence, it is assumed that the alternative cementitious material produced by the hydrothermal method can be considered as an alternative binder for the fabrication of mortar and concrete.

\subsection{Compressive Strength}

In this investigation, the mortar samples were fabricated using the ACM, sand and varying amounts of water and alkali activator. Table 2 depicts the mix proportion and sample code of the different types of the mortar samples. In this study, six samples from each batch were tested to obtain an average result of the compressive strength. Figure 11 shows the compressive strength of the control as well as ACM based mortar. As presented in the figure, the compressive strength of control mortar (CCM), ACM-M1 (ACM denotes alternative cementitious material and $\mathrm{M}$ indicates mortar), ACM-M2, and ACM-M3 is measured to be $34.2 \pm 1.2, \quad 25.4 \pm 1.5, \quad 28.6 \pm 1.2, \quad 33.8 \pm 1.3 \mathrm{MPa}$, respectively. Additionally, it is envisaged that the compressive strength of the ACM based mortar increases gradually with the increase in alkali activator content. Interestingly, the compressive strength of the ACM based mortar fabricated using the maximum amount of alkali activator (ACM-M3) is observed to be comparable with the control mortar. The lower compressive strength of the mortar prepared using less extent of alkali activator is observed to be due to the inadequate hydration of the alternative cementitious material. In

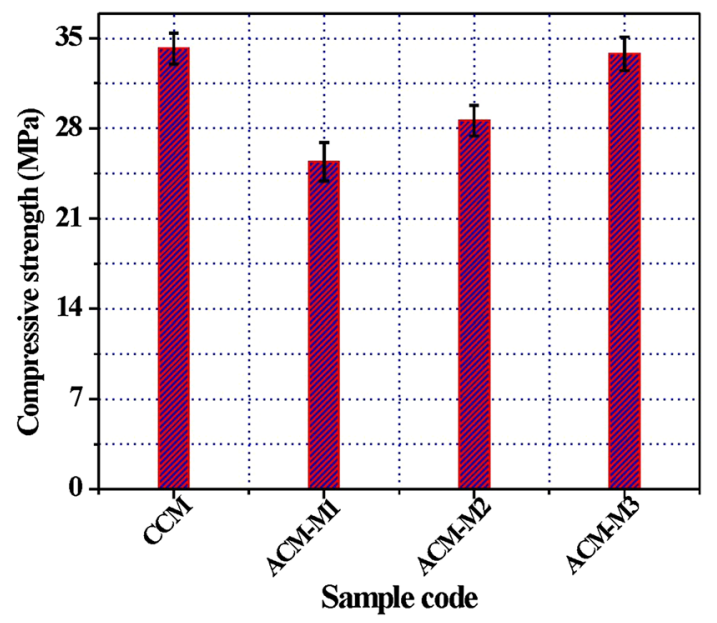

Fig. 11 Compressive strength of the 28 days cured control cement mortar (CCM) and alternative cement based mortar (ACM-M1, ACM-M2, ACM-M3).

fact, due to the lack of driving force to transpire the hydration of the alternative cementitious material in the presence of water (Jo et al. 2014a), the ACM demands high dose of alkali activator. The high dose of alkali activator supplies the driving force for the hydration of the alternative cementitious material, which in turn develops a compact microstructure. Eventually, the strength of the mortar increases. Hence, it is demonstrated that the ACM based mortar possesses a strong ability to gain strength in the presence of alkali activator. Accordingly, it is apparent that the alternative cementitious material could be used as a primary binder for the fabrication of mortar and concrete.

\section{Discussion}

Viewing in light of the results presented in the preceding sections, it is apparent that the aqueous carbonation of slaked lime can accumulate the $\mathrm{CO}_{2}$. Additionally, the hydrothermal method successfully produces a cementitious material utilizing the aqueous carbonated lime. In this section, we have tried to establish a reaction scheme for the aqueous the carbonation of the slaked lime and a plausible model for the hydrothermal synthesis of the cementitious material. The Eq. (2) represents a plausible reaction scheme for the carbonation of the slaked lime. Figure 12 depicts the plausible schematic view of the carbonation reaction steps. At the beginning of the carbonation reaction, the slaked lime solution contains the calcium $\left(\mathrm{Ca}^{2+}\right)$ and hydroxyl ion $\left(\mathrm{OH}^{-}\right)$(Eq. (3)) (Olajire 2013), which in turn increases the $\mathrm{pH}$ of the solution (12.4). However, the purging of $\mathrm{CO}_{2}$ into the reaction medium leads to decrease the $\mathrm{pH}$ of the reaction system by dissolving the $\mathrm{CO}_{2}$ in the aqueous medium (Eq. 4). During this time, the aqueous $\mathrm{CO}_{2}$ reacts with hydroxyl ions $\left(\mathrm{OH}^{-}\right)$to form bicarbonate ions (Eq. (5)). However, the lifetime of this bicarbonate ion in the alkali medium is very small (Han et al. 2011), which, therefore, reacts with the other hydroxyl ion to form a carbonate ion and water (Eq. (6)). In fact, in this step, the hydroxyl ions 


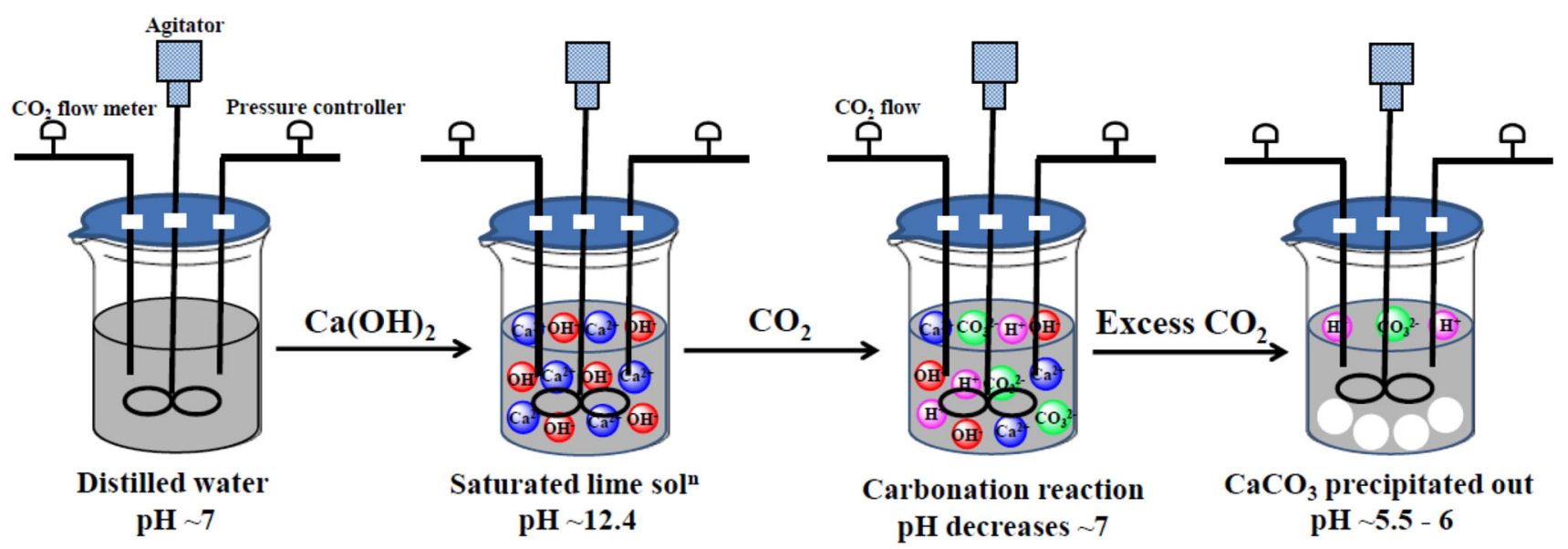

Fig. 12 The plausible schematic view of the carbonation reaction steps.

are consumed to neutralize the bicarbonate ions (Han et al. 2011), which in turn leads to reduce the $\mathrm{pH}$ of the medium. Additionally, in this step, due to the production of water, the total volume of water in the reaction system increases, which in turn reduces the $\mathrm{OH}^{-}$concentration in the per unit volume of water. Eventually, the $\mathrm{pH}$ of the reaction medium decreases. Finally, the aqueous medium contains the calcium $\left(\mathrm{Ca}^{2+}\right)$ and carbonate $\left(\mathrm{CO}_{3}{ }^{2-}\right)$ ions. The combination of these two ions forms the calcium carbonate as a white color precipitate (Eq. 7). The excess amount of $\mathrm{CO}_{2}$ may present in the aqueous medium in the form of carbonic acid, which may lead to decrease the $\mathrm{pH}$ of the medium below 6 (Fig. 12).

$$
\begin{aligned}
& \mathrm{Ca}(\mathrm{OH})_{2}+\mathrm{CO}_{2}+\mathrm{H}_{2} \mathrm{O} \rightarrow \mathrm{CaCO}_{3}+2 \mathrm{H}_{2} \mathrm{O} \\
& \mathrm{Ca}(\mathrm{OH})_{2}(\mathrm{~S}) \rightleftharpoons \mathrm{Ca}^{2+}(\mathrm{Aq})+2 \mathrm{OH}^{-}(\mathrm{Aq}) \\
& \mathrm{CO}_{2}(\mathrm{~g}) \rightleftharpoons \mathrm{CO}_{2}(\mathrm{Aq})
\end{aligned}
$$<smiles></smiles>

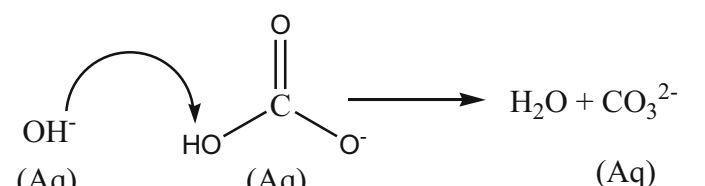

(Aq)

$$
\text { (Aq) }
$$

$$
\mathrm{Ca}^{2+}(\mathrm{Aq})+\mathrm{CO}_{3}^{2-}(\mathrm{Aq}) \longrightarrow \mathrm{CaCO}_{3}(\mathrm{~S}) \downarrow
$$

The carbonated material produced from the aqueous carbonation was used for the hydrothermal synthesis of the cementitious material. In this study, the alternative cementitious material was produced using aqueous carbonated lime infused with silica and hydrated alumina. Figure 2 represents a plausible model for the hydrothermal synthesis of the cementitious material. Xu and Deventer (2000) stated that a geopolymer compound can be produced from the silica infused with hydrated alumina. Hence, it is assumed that the alternative cementitious material produced in this investigation may contain geomaterial. During the hydrothermal synthesis, the mixture of the silica fume and calcium carbonate may produce a calcium bonded hydrated silica, (Eq. 8). Additionally, the hydrolysis of sodium aluminate may produce a hydrated alumina (Eq. (9)). After aging, the compounds produced by the hydrolysis (Eqs. (8) and (9)) lead to produce the gel. Subsequently, the mixing of these gel compounds may produce the calcium bonded aluminosilicates (Eq. 10). As the alternative cementitious material contains calcium-substituted aluminosilicate geopolymer compound, therefore, the hydration of this cementitious material in the presence of the water is difficult. This could be due to the lack of driving force to initiate the hydration reaction of the alternative cementitious material (Jo et al. 2014a). Nevertheless, the use of alkaline solution (50\% $\mathrm{NaOH})$ may supply the driving force to initiate the hydration reaction and lead to hardening the sample. During the hydration of the ACM in the presence of alkali activator, the mixture of geopolymer compounds may produce an interpenetrating net structure of the hydrated alumino-silicate compounds (Xu and Deventer 2000). Particularly, the hydration of the alternative cementitious material possibly produces the calcium-sodium aluminosilicate hydrate gel (Myers et al. 2013; Kar et al. 2014), which may hold the crystalline component and develop a compact 


$$
\begin{aligned}
& \mathrm{SiO}_{2}+\mathrm{CaCO}_{3}+\mathrm{H}_{2} \mathrm{O} \longrightarrow(\mathrm{HO})_{3} \mathrm{Si}-\mathrm{O}-\mathrm{Si}(\mathrm{OH})_{3}+\mathrm{CaCO}_{3}+ \\
& \left.\left.\qquad \begin{array}{l}
{[} \\
\mathrm{Si}(\mathrm{OH})_{2}-\mathrm{O}-\mathrm{Si}(\mathrm{OH})_{2}
\end{array}\right]_{\mathrm{n}} \mathrm{O}-\mathrm{Ca}-\mathrm{Si}(\mathrm{OH})_{2}-\mathrm{O}-\mathrm{Si}(\mathrm{OH})_{2}\right]_{\mathrm{n}}
\end{aligned}
$$

microstructure. This phenomenon may, therefore, contribute to enhancing the strength of the ACM based mortar.

$$
\mathrm{NaAlO}_{2}+\mathrm{H}_{2} \mathrm{O}+\mathrm{NaOH} \rightarrow \mathrm{NaAl}^{-}(\mathrm{OH})_{4}
$$

carbonate $(0.0116 \pm 0.0003 \mathrm{~mol})$. Besides, the alternative cementitious material was synthesized using the carbonated lime produced by the reaction condition $\mathrm{B}$. Based on the particle size analysis, setting time measurement and com-

Prod. of Eq (8) + Prod. of Eq $(9) \longrightarrow\left[-\mathrm{Si}(\mathrm{OH})_{2}-\mathrm{O}-\mathrm{Al}(\mathrm{OH})_{2}\right]_{\mathrm{n}}+$

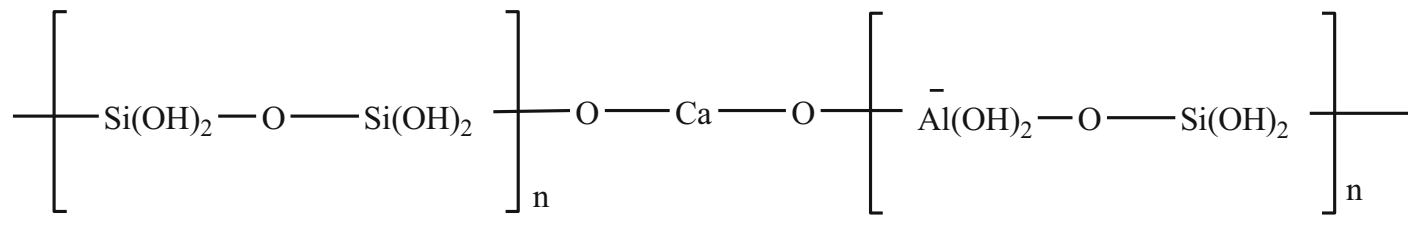

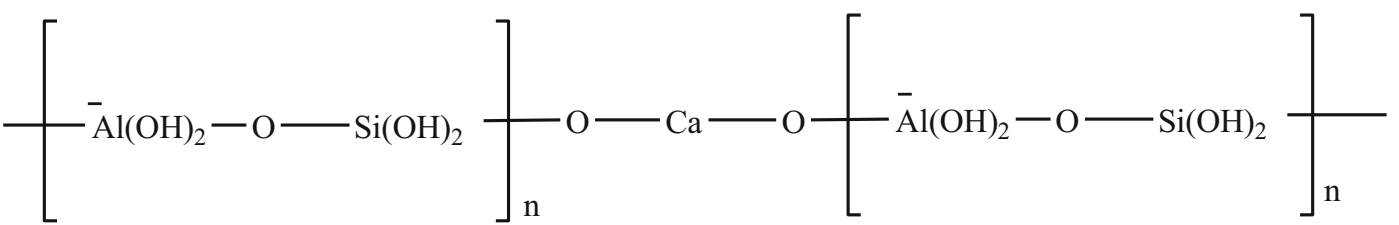

\section{Conclusions}

The paper presents a unique technique to produce an using the aqueous carbonated lime, silica fume, and hydrated alumina. Prior to producing the ACM, the aqueous carbonation of the slaked lime was performed in four different conditions to produce the carbonated lime. Analyzing the carbonated product using different analytical tools such as TGA, XRD, and FESEM, it is revealed that the carbonated product is calcium carbonate (calcite). Additionally, it is predicted that the carbonation reaction condition $\mathrm{B}$ (agitation speed 200 RPM and $\mathrm{CO}_{2}$ injection speed $0.5 \mathrm{l} / \mathrm{min}$ ) consumes a maximum amount carbon dioxide $(0.0118 \pm 0.0008 \mathrm{~mol}$ or $100.1 \%$ with respect to moles of slaked lime) and produces a maximum amount of calcium pressive strength analysis, it is demonstrated that the ACM can control the physical and mechanical properties of the mortar. The compressive strength of the ACM based mortar (ACM-M3) prepared using the maximum amount of alkali activator is measured to be $33.8 \pm 1.3 \mathrm{MPa}$, whilst the same is measured to be $34.2 \pm 1.2$ for the control mortar. Interestingly, it is revealed that the compressive strength of the ACM based mortar increases gradually with the increase in alkali activator content. Moreover, a plausible model has been proposed to explain the aqueous carbonation and the synthesis of the ACM. Hence, it is concluded that an alternative cementitious material can be produced by the hydrothermal method utilizing aqueous carbonated lime, which could be used as a primary binder for the fabrication of mortar. Accordingly, the utilization of the aqueous 
carbonated lime in producing a cementitious material is assumed to be an initial alternative approach to reduce the atmospheric $\mathrm{CO}_{2}$.

\section{Acknowledgments}

Author would like to acknowledge the BK21+, the Government of Korea (Republic of) for their funding to pursue this research program.

\section{Open Access}

This article is distributed under the terms of the Creative Commons Attribution 4.0 International License (http://creativecommons.org/licenses/by/4.0/), which permits unrestricted use, distribution, and reproduction in any medium, provided you give appropriate credit to the original author(s) and the source, provide a link to the Creative Commons license, and indicate if changes were made.

\section{References}

Amato, I. (2013). Concrete solutions. Nature News, 494, 300-301.

Chakraborty, S., Kundu, S. P., Roy, A., Adhikari, B., \& Majumder, S. B. (2013). Effect of jute as fiber reinforcement controlling the hydration characteristics of cement matrix. Industrial and Engineering Chemistry Research, 52, 1252-1260.

Chen, Z. Y., O’Connor, W. K., \& Gerdemann, S. J. (2006). Chemistry of aqueous mineral carbonation for carbon sequestration and explanation of experimental results. Environmental Progress \& Sustainable Energy, 25(2), 161-166.

Chindaprasirt, P., \& Cao, T. (2015). Setting, segregation and bleeding of alkali-activated cement mortar and concrete binders. In F. P. Torgal, J. A. Labrincha, C. Leonelli, A. Palomo, \& P. Chindaprasirt (Eds.), Handbook of alkaliactivated cements, mortars and concretes (pp. 113-131)., Woodhead Publishing series in Civil and Structural Engineering, No.: 54 Cambridge: Woodhead publishing.

Chizmeshya, A. V. G., McKelvy, M. J., Marzke, R., Ito, N., Wolf, G., Bèarat, H., et al. (2007) Investigating geological sequestration reaction processes under in situ process conditions. 32nd International Technical Conference on Coal Utilization \& Fuel Systems, 441.

Criado, M., Fernandez-Jimenez, A., \& Palomo, A. (2010). Alkali activation of fly ash. Part III: effect of curing conditions on reaction and its graphical description. Fuel, 89, 3185-3192.

Crowley, S. F. (2010). Mineralogical and chemical composition of international carbon and oxygen isotope calibration material NBS 19, and reference materials NBS 18, IAEACO-1 and IAEA-CO-8. Geostandards and Geoanalytical Research, 34(2), 193-206.
Dinakar, P., Sahoo, P. K., \& Sriram, G. (2013). Effect of metakaolin content on the properties of high strength concrete. International Journal of Concrete Structures and Materials, 7(3), 215-223.

Feely, R. A., Sabine, C. L., Lee, K., Berelson, W., Kleypas, J., Fabry, V. J., et al. (2004). Impact of anthropogenic $\mathrm{CO}_{2}$ on the $\mathrm{CaCO}_{3}$ system in the oceans. Science, 305, 362-366.

Galan, I., Andrade, C., Mora, P., \& Sanjuan, M. A. (2010). Sequestration of $\mathrm{CO}_{2}$ by concrete carbonation. Environmental Science and Technology, 44, 3181-3186.

Gerdemann, S. J., O’Connor, W. K., Dahlin, D. C., Penner, L. R., \& Rush, H. (2007). Ex-situ aqueous mineral carbonation. Environmental Science and Technology, 41, 2587-2593.

Han, S. J., Yoo, M., Kim, D. W., \& Wee, J. H. (2011). Carbon dioxide capture using calcium hydroxide aqueous solution as the absorbent. Energy \& Fuels, 25, 3825-3834.

Hanchen, M., Prigiobbe, V., Baciocchi, R., \& Mazzotti, M. (2008). Precipitation in the mg-carbonate system effects of temperature and $\mathrm{CO}_{2}$ pressure. Chemical Engineering Science, 63, 1012-1028.

Huijgen, W. J. J., Comans, R. N. J. (2005). Carbon dioxide sequestration by mineral carbonation. Literature review update (2003-2004), ECN-C-05-022. Energy Research Centre of The Netherlands, Petten, Netherlands. Available at: http://www.ecn.nl/docs/library/report/2005/c05022.pdf. Accessed: 23 Dec 2014.

Huijgen, W. J. J., Comans, R. N. J., \& Witkamp, G. J. (2007). Cost evaluation of $\mathrm{CO}_{2}$ sequestration by aqueous mineral carbonation. Energy Conversion and Management, 48, 1923-1935.

Huijgen, W. J. J., Witcamp, G. J., \& Comans, R. N. J. (2004). Mineral $\mathrm{CO}_{2}$ sequestration in alkaline solid residues. Proceedings Materials of 7th International Conference on Greenhouse Gas Control Technologies (pp. 2415-2418) Vancouver, BC.

Huijgen, W. J. J., Witkamp, G. J., \& Comans, R. N. J. (2006). Mechanisms of aqueous wollastonite carbonation as a possible $\mathrm{CO}_{2}$ sequestration process. Chemical Engineering Science, 61, 4242-4251.

Jacobsen, J., Rodrigues, M. S., Telling, M. T. F., Beraldo, A. L., Santos, S. F., Aldridge, L. P., et al. (2013). Nano-scale hydrogen-bond network improves the durability of greener cements. Scientific Reports, 3(2667), 1-6. doi: 10.1038/srep02667.

Jeon, D., Jun, Y., Jeong, Y., \& Oh, J. E. (2015). Microstructural and strength improvements through the use of $\mathrm{Na}_{2} \mathrm{CO}_{3}$ in a cementless $\mathrm{Ca}(\mathrm{OH})_{2}$-activated Class $\mathrm{F}$ fly ash system. $\mathrm{Ce}$ ment and Concrete Research, 67, 215-225.

Jiao, J., Liu, X., Gao, W., Wang, C., Feng, H., Zhao, X., et al. (2009). Two-step synthesis flowerlike calcium carbonate/ biopolymer composite materials. CrystEngComm, 11, 1886-1891.

Jo, B. W., Chakraborty, S., Jo, J. H., \& Lee, Y. S. (2015). Effectiveness of carbonated lime as a raw material in producing a $\mathrm{CO}_{2}$-stored cementitious material by the hydrothermal method. Construction and Building Materials, 95, 556-565. 
Jo, B. W., Chakraborty, S., \& Kim, K. H. (2014a). Investigation on the effectiveness of chemically synthesized nano cement in controlling the physical and mechanical performances of concrete. Construction and Building Materials, 70, 1-8.

Jo, B. W., Chakraborty, S., Kim, K. H., \& Lee, Y. S. (2014b). Effectiveness of the top-down nanotechnology in the production of ultrafine cement ( $220 \mathrm{~nm})$. Journal of Nanomaterials, 57, 1-9.

Jo, B. W., Chakraborty, S., \& Yoon, K. W. (2014c). Synthesis of a cementitious material nanocement using bottom-up nanotechnology concept: An alternative approach to avoid $\mathrm{CO}_{2}$ Emission during production of cement. Journal of Nanomaterials, 97, 1-12.

Juenger, M., Winnefeld, F., Provis, J., \& Ideker, J. (2011). Advances in alternative cementitious binders. Cement and Concrete Research, 41, 1232-1243.

Kar, A., Ray, I., Halabe, U. B., Unnikrishnan, A., \& DawsonAndoh, B. (2014). Characterizations and quantitative estimation of alkali-activated binder paste from microstructures. International Journal of Concrete Structures and Materials, 8(3), 213-228.

Keeling, C. D., Whorf, T. P., Wahlen, M., \& VanderPlicht, J. (1995). Inter-annual extremes in the rate of rise of atmospheric carbon dioxide since 1980. Nature, 75, 666-670.

Kim, M. S., Jun, Y., Lee, C., \& Oh, J. E. (2013). Use of $\mathrm{CaO}$ as an activator for producing a price competitive non-cement structural binder using ground granulated blast furnace slag. Cement and Concrete Research, 54, 208-214.

Kontoyannis, C. G., \& Vagenas, N. V. (2000). Calcium carbonate phase analysis using XRD and FT-Raman spectroscopy. Analyst., 125, 251-255.

Kotwal, A. R., Kim, Y. J., Hu, J., \& Sriraman, V. (2015). Characterization and early age physical properties of ambient cured geopolymer mortar based on class C fly ash. International Journal of Concrete Structures and Materials, 9(1), 35-43.

KSF 2405. (2010). Testing method for compressive strength of concrete. Seoul, Korea: Bureau of Korean standard (in Korean).
KSL 5108. (2007). Testing method for setting time of hydraulic cement by vicat needle. Seoul, Korea: Bureau of Korean standard (in Korean).

KSL 5201. (2013). Portland cement. Seoul, Korea: Bureau of Korean standard (in Korean).

Metz, B., Davidson, O., deConinck, H., Loos, M., \& Meyer, L., (Eds.) (2005). IPCC special report on carbon dioxide capture and storage. Cambridge University Press, New York, NY: 431. Available at: http://www.ipcc.ch/pdf/special-reports/srces/src cs_wholereport.pdf. Accessed: 4 Nov 2014.

Myers, R. J., Bernal, S. A., Nicolas, R. S., \& Provis, J. L. (2013). Generalized structural description of calciumsodium aluminosilicate hydrate gels: The cross-linked substituted tobermorite model. Langmuir, 29, 5294-5306.

Olajire, A. A. (2013). A review of mineral carbonation technology in sequestration of $\mathrm{CO}_{2}$. Journal of Petroleum Science and Engineering, 109, 364-392.

Phair, J. (2006). Green chemistry for sustainable cement production and use. Green Chemistry, 8, 763-780.

Roychand, R., De Silva, S., Law, D., \& Setunge, S. (2016). Micro and nano engineered high volume ultrafine fly ash cement composite with and without additives. International Journal of Concrete Structures and Materials. doi: 10.1007/s40069-015-0122-7.

Schrabback, J. M. (2010). Concepts for 'green' cement. ICR. Available at: www.sika.com/dms/get//Concepts $\% 20$ for $\%$ 20Green\%20Cement.pdf. Accessed 11 March 2015.

Siegenthaler, U., \& Oeschger, H. (1987). Biospheric CO2 emissions during the past 200 years reconstructed by deconvolution of ice core data. Tellus, 39B, 140-154.

Stutzman, P.E. (1996). Guide for X-ray powder diffraction analysis of portland cement clinker. NISTIR 5755. Building and fire research laboratory, National Institute of standards and Technology, U.S Department of Commerce, Gaitheresburg, MD. Available at: http://fire.nist.gov/bfrlpu bs/build96/PDF/b96138.pdf. Accessed 4 Nov 2014.

$\mathrm{Xu}$, Hua, \& Van Deventer, J. S. J. (2000). The geopolymerisation of alumino-silicate minerals. International Journal of Mineral Processing, 59, 247-266. 